\title{
Inspeção escolar no contexto das políticas de gestão democrática de educação
}

\section{School inspection in the context of democratic educational management policies}

\author{
DOI: $10.46814 /$ lajdv3n5-015
}

Recebimento dos originais: 01/05/2021

Aceitação para publicação: 31/06/2021

\author{
Érica Giaretta Biase \\ Mestrado acadêmico em Educação/Unicamp. Doutoranda em Educação /Faced-Ufu. \\ Universidade Federal de Uberlândia \\ E-mail: ericabiase@yahoo.com.br \\ Flávia Junqueira da Silva \\ Mestrado acadêmico em Educação/Ufu. Doutoranda em Educação/Faced-Ufu. \\ Universidade Federal de Uberlândia \\ E-mail: flaviajusilva@ hotmail.com
}

\section{RESUMO}

A pesquisa propõe uma apresentação teórica do processo de formação do Inspetor Escolar a partir da perspectiva democrática da educação. Nessa perspectiva, buscamos compreender as políticas educacionais e identificar os aspectos relevantes para a formação do especialista em inspeção escolar. Nesse sentido, algumas indagações são apresentadas: como tem ocorrido a formação dos especialistas em educação na área da inspeção escolar a partir da perspectiva democrática? Quais são as atribuições do inspetor escolar na gestão democrática? Historicamente, o surgimento do trabalho da inspeção escolar no Brasil iniciou com a vinda dos Jesuítas. A partir daí, mudanças aconteceram no cenário político e educacional no país, o que contribuiu para a democratização do ensino e a busca de um novo perfil deste profissional. Os cursos de graduação em Pedagogia e de pós-graduação lato sensu têm grande responsabilidade na formação deste profissional, no desenvolvimento de um ensino com bases epistemológicas centradas no contexto filosófico, sociológico, político, social, histórico, econômico e cultural. Dessa forma, o estudo teórico, a princípio partiu do levantamento bibliográfico sobre a temática. E, após a seleção do material coletado, utilizou-se das análises textuais e interpretativas das fontes selecionadas. Dessa forma, recorreu-se a vários teóricos e pesquisadores da área como Santos Filho (2006), Veiga (2003), Gadotti (2000), Barbosa (2008), Laval (2019), entre outros. Assim, as instituições educacionais necessitam de profissionais preparados como uma formação acadêmica solidificada para atuarem no processo ensino aprendizagem na construção de uma educação baseada nos princípios da democracia, da inclusão e da formação humana. Portanto, o inspetor escolar deve atuar como gestor educacional estimulando o trabalho em equipe, o diálogo entre os profissionais da educação, a busca por novas técnicas e metodologias de ensino, valorizar as experiências dos envolvidos no processo e integrar a comunidade na solução dos problemas, na busca por um processo construtivo e integrador de ensino.

Palavras-chave: Inspeção Escolar. Educação. Ensino. Democracia. Gestão.

\section{ABSTRACT}

This research proposes a theoretical presentation on the training process of the school inspector from the democratic perspective of education. From this perspective, we seek to understand the educational policies and identify the relevant aspects for the formation of the school inspection specialist. In this 
sense, some questions are presented: How has the training of specialists in education in the area of school inspection occurred from the democratic perspective? What are the attributions of the school inspector in democratic management? Historically, the emergence of school inspection in Brazil began with the arrival of the Jesuits. Since then, changes have taken place in the political and educational scenario in the country, which contributed to the democratization of education and the search for a new profile for this professional. The graduate courses in Pedagogy and the lato sensu post-graduate courses have a great responsibility in the formation of this professional, in the development of a teaching with epistemological bases centered on the philosophical, sociological, political, social, historical, economic and cultural context. In this way, the theoretical study started with a bibliographical survey on the theme. And, after the selection of the collected material, we used textual and interpretative analyses of the selected sources. Thus, we resorted to several theorists and researchers in the area such as Santos Filho (2006), Veiga (2003), Gadotti (2000), Barbosa (2008), Laval (2019), among others. Thus, educational institutions need professionals prepared as a solidified academic training to act in the teaching-learning process in the construction of an education based on the principles of democracy, inclusion and human formation. Therefore, the school inspector should act as an educational manager stimulating teamwork, dialogue among education professionals, the search for new techniques and teaching methodologies, valuing the experiences of those involved in the process and integrating the community in the solution of problems, in the search for a constructive and integrating teaching process.

Key-words: School Inspection. Education. Teaching. Democracy. Management.

\section{INTRODUÇÃO}

As propostas de formação e construção do papel do inspetor escolar no processo educacional se baseiam numa política democrática que são delineadas a partir do processo histórico da educação brasileira. E que são direcionadas pelas mudanças exigidas no sistema educacional, conforme são exigidos documentos oficiais e pautados nas discussões de questões políticas, culturais, pedagógicas nacionais e internacionais.

O interesse em delinear e discutir a questão da formação dos gestores educacionais centralizados, a priori, no inspetor escolar surge diante das discussões no cenário educacional e na tentativa de formação de um "novo" perfil deste profissional, que historicamente é visto como um fiscalizador.

Diante deste cenário surge à problemática que norteou a proposta de trabalho: o que deve ser priorizado na formação do Inspetor Educacional dentro de uma proposta democrática de ensino?

Compreende-se que a pesquisa expande a dimensão científica e social e abrange a dimensão política e histórica, a partir do projeto articulador e amplo contemplando questões do processo democrático da educação brasileira.

Por isso, o intuito principal do estudo foi analisar o processo de formação do Inspetor Educacional numa perspectiva democrática da educação. Para isso fez-se necessário compreender historicamente a formação dos gestores educacionais, em especial, o Inspetor Escolar a partir das 
inovações nas políticas educacionais; E identificar os principais aspectos relevantes, a priori, para a formação dos gestores educacionais - Inspeção Escolar - num processo de gestão política, administrativa e pedagógica transformadora da educação.

Assim, acredita-se que a abordagem temática em estudo tem seu papel na construção de uma realidade centralizada no processo de formação dos principais profissionais responsáveis a desenvolver e acreditar numa educação de qualidade. Por isso, faz-se necessário analisar os cursos de pós-graduação na área da educação, focando o processo de formação continuada.

\section{METODOLOGIA DE PESQUISA}

Para a realização deste estudo utilizou-se da pesquisa bibliográfica a fim de situar a temática e buscar parâmetros, conceitos, definições e estudos de diversos pesquisadores dentro da proposta pesquisada. Também, foi necessário utilizar-se da pesquisa documental para a maior compreensão do tema e fundamentação dos objetivos propostos.

Como método, fez-se necessário utilizar-se do método dedutivo, no qual a análise geral do tema proporcionará uma discussão real e concreta do assunto proposto, contribuindo para uma interação mais próxima do tema.

Adotou como procedimentos técnicos para a pesquisa bibliográfica a análise textual, temática e interpretativa das obras em estudo. E para a pesquisa documental a análise histórica dos documentos encontrados.

\section{O PAPEL DO INSPETOR ESCOLAR NO PROCESSO DEMOCRÁTICO}

As políticas educacionais no Brasil, pautadas no discurso da modernização, priorizam a descentralização e o novo gerenciamento educacional.. Isso indica uma tendência à fragmentação do sistema educativo das políticas de gestão, sustentadas pelos conceitos de autonomia, descentralização, flexibilidade, individualização e poder local. Assim, a gestão de pessoas assume importância estratégica possibilitando um ambiente de trabalho saudável e propício ao desenvolvimento individual, interpessoal e institucional (LAVAL, 2019).

A Inspeção Escolar está ligada a vários fatores que contribuem com o processo democrático da comunidade escolar. Evidentemente, nem sempre foi assim. A própria expressão linguística nos remete à história, desde o Brasil colonial, de que o ato de inspecionar nos lembra do ato de fiscalizar, observar, examinar, verificar, olhar, vistoriar, controlar, vigiar...

Porém, atualmente, a figura deste profissional nas instituições escolares proporciona uma estreita ligação entre os outros órgãos do Sistema Educacional, quer sejam Secretarias, quer sejam Regionais e Unidades Escolares, para garantir a aplicação legal do regime democrático. Por isso, o 
Inspetor Escolar tem uma grande concentração nos aspectos Administrativos, Financeiros e Pedagógicos das Unidades Escolares, trabalhando inclusive, como agente sociopolítico. (CONSELHO NACIONAL DE EDUCAÇÃO, 2009).

Neste sentido, o Inspetor Escolar trabalha estreitamente com a gestão de pessoal e gestão administrativo-pedagógica. Está sempre preocupado com a veracidade e atualização da escrituração e organização escolar para proporcionar segurança no processo de arquivos e no futuro, seja qual for o tempo, que a documentação esteja resguardada para servir de acervo de pesquisas históricas ou para a situação funcional dos servidores para efeitos legais, bem como para a vida escolar do estudante ao longo de seu percurso educacional. Em qualquer tempo, as pessoas poderão procurar a sua instituição escolar de origem para requerer um novo documento, como o Histórico Escolar, por exemplo.

O Inspetor Escolar possibilita assegurar o acervo de escrituração escolar e essa é condição imprescindível de atuação profissional., pois não se sabe quando alguém que conhece e trabalha na instituição Escolar ainda estará ou nem se lembrará das situações, casos ou momentos ocorridos; ou seja, as equipes de trabalhos estão sempre se renovando e acaba necessitando de uma Escrituração dos fatos, ato na Organização escolar muito bem definida para resguardar a integridade de todo arquivo (Atas, Diários de Classe, Fichas individuais e entre outros).

Inclusive, como o Inspetor Escolar está sempre em contato com as comunidades escolares, conforme demandas das instituições escolares e tem um papel importante na comunicação entre os órgãos da administração superior do sistema e os estabelecimentos de ensino que o integram, pois direcionam -se para a coordenação e desenvolvimento da escola e educação, a sistematização funcional da equipe docente e dos estudantes, também a presença dos registros e documentação escolar que colaboram com o êxito do processo escolar (CONSELHO ESTADUAL DE EDUCAÇÃO/MG, 2009).

Por isso, este profissional, como prática educativa, se torna um importante agente político e de caráter pedagógico do sistema, pois poderá sugerir mudanças de estratégias nas decisões dos órgãos do sistema para promover uma implementação organizacional mais ampla e democrática para garantir acesso de toda sociedade nas Instituições Escolares, ao conhecimento e à cultura.

Pensando nisso, os estudos e aplicação das normas do Sistema observadas pelo Inspetor Escolar, o faz posicionar diante de uma pragmática de educação, sociedade, modelos de organização e funcionamento, prática pedagógica e valores das práticas de conscientização e discussões. Dessa forma, como discute Barbosa (2008) o trabalho que o inspetor escolar executa deve ser repercutido a toda equipe da escola de forma que ocorra uma discussão coletiva na operacionalização do trabalho pedagógico e administrativo.

Ainda, conforme Barbosa (2008), o trabalho do inspetor depende da participação de todos os segmentos da escola, de forma responsável para o desenvolvimento de uma prática pedagógica com 
sucesso. É necessário também que os profissionais envolvidos no processo façam constantemente a avaliação dos resultados obtidos desse trabalho conjunto, a fim de diagnosticar a qualidade desse empreendimento educacional, e buscar alternativas que possam melhorar a prática educativa.

Nesse processo democrático de educação, a inspeção escolar tem um papel fundamental e uma ação direcionada a acompanhar e orientar a equipe da escola, subsidiando-a nos seus aspectos pedagógicos e administrativos. Dessa forma, deve propiciar a melhoria do processo ensino aprendizagem e se integrando como um profissional dentro da instituição escolar responsável pelo processo educativo. Para isso, este deve conhecer a realidade escolar e se inteirar dos fatos com clareza nos diversos ambientes da instituição, propiciando uma intervenção mais segura e justa.

As ações do Inspetor não se limitam, evidentemente, apenas nas aplicações de normas, mas, também, nas ações de revisão ou mudanças na legislação, numa perspectiva crítica adequada à realidade social a que se destina, dando conhecimento à administração do Sistema das consequências da aplicação dessas mesmas normas.

Sob o ponto de vista ideológico, o Inspetor Escolar quando age criticamente nos aspectos educacionais no momento da aplicação da legalidade pode contribuir nas reformulações das leis, possibilitando influências ao legislador ou órgãos normativos sob o ponto de vista do ato de educar. Ou melhor, o Inspetor Escolar possibilita a conversão do conteúdo ideológico da legislação do ensino em diretrizes capazes de orientar a ação dos agentes do Sistema. Por isso, é um agente Político. (CONSELHO NACIONAL DE EDUCAÇÃO, 2009).

Portanto, o papel do Inspetor Escolar no processo democrático é de fundamental importância social sob o ponto de vista educacional, pois se torna os "olhos", a presença ou a representação da ação do Estado ou do órgão executivo e Legislativo "in loco", nas Instituições de Ensino. Inclusive, por causa da aplicação das normas que podem ser verificadas a sua adequação na práxis operativa do Sistema Educacional.

Por fim, o processo democrático, na função do Inspetor Escolar é captar os efeitos da aplicação da norma com o objetivo de promover a desejada adequação do "formal" ao "real" e vice-versa com uma função dialógica, orientadora e analítica das dos interesses e conhecimentos oriundos das bases do sistema, zelando pelos direitos e deveres da comunidade atendida tanto externa quanto interna do ambiente escolar e dos órgãos normativos por quais desempenha sua função.

Conforme a Lei Complementar n ${ }^{\circ} .663 / 2019$ do município de Uberlândia, as atribuições do inspetor escolar compreendem atividades de natureza pedagógica e administrativa, que se relacionam na orientação e apoio às instituições educacionais e também na normatização de ações favoráveis aos estabelecimentos educacionais, conforme legislação vigente. Além disso, acrescentamos como atribuição do Inspetor Escolar, conforme a lei complementar: 
Colaborar com a equipe da escola em projetos e experiências pedagógicas que proponham melhoria do processo de ensino-aprendizagem; Acompanhar e orientar quanto ao preenchimento correto do censo escolar, livro de ponto, diários de classe, livro de transferências expedidas, livro de registro de matrículas, livro de atas de resultados finais, livro de atas de exames especiais, ficha de matrícula, histórico escolar, ficha individual, sistema web; Verificar sempre que necessário a documentação dos alunos, dando atenção especial aos anos iniciais e finais e passar as orientações necessárias (UBERLÂNDIA, 2019)

Com a Lei Complementar $n^{\circ}$. 663/2019 verifica-se que as atribuições do Inspetor escolar direcionam para atividades específicas do cargo que legitimam o trabalho pedagógico com características fundamentais para a organização e orientações fundamentais para o sucesso das atividades educacionais. Além disso, destacamos ainda como atribuições do cargo questões que envolvem a parte pedagógica do ensino.

\begin{abstract}
Acompanhar a elaboração e implementação do Projeto Político-Pedagógico da escola; Incentivar, participar e apreciar as atividades culturais promovidas pela escola, visando ao fortalecimento da relação entre família e escola; Fiscalizar o cumprimento da legislação nas parcerias entre a Secretaria Municipal de Educação e os membros da rede de proteção à criança e ao adolescente; Participar da avaliação de estágio probatório do servidor não estável quando designado; Orientar a escola na elaboração e atualização do regimento escolar, quadro curricular e calendário escolar, resguardando as normas legais vigentes, acompanhando o seu cumprimento (UBERLÂNDIA, 2019)
\end{abstract}

Ao analisar as atribuições específicas do cargo Inspeção Escolar compreendemos o quanto as atividades são amplas e abrangentes, no campo pedagógico e administrativo. Ao mesmo tempo apresenta olhares específicos para questões pontuais e fundamentais no interior das instituições escolares.

Por isso, é importante enfatizar alguns aspectos relevantes da formação do inspetor escolar a partir das políticas democráticas da educação. Pois, como profissional sua função tem relação direta com a escola e os órgãos responsáveis pelos encaminhamentos legislativos da educação.

\title{
4 FORMAÇÃO DO INSPETOR ESCOLAR
}

Ao longo da história, percebe-se que as instituições de ensino superior apresentam características políticas, econômicas, intelectuais, jurídicas próprias que exigem e necessitam ser avaliadas e reavaliadas. Essas avaliações apontam algumas das principais crises enfrentadas por esses estabelecimentos, ora crises de gestão, ora pedagógicas, de autonomia, de modelo, de função. Isto é, crises que afetam a qualidade do processo de construção do conhecimento.

O processo de avaliação institucional vem ao encontro da busca de qualidade da academia, defendido e discutido por muitas décadas com o intuito de transformar o ensino superior. Santos Filho (2006) diz que a educação superior "tem o papel de formar jovens capazes para desempenhar uma 
atividade profissional útil à sociedade, prepará-los para exercer o papel de cidadãos numa sociedade democrática e ajudá-los a compreender e a partilhar a cultura comum ocidental” (p.2).

E ainda, as Instituições de Ensino Superior (IES) têm priorizado a formação profissional/especialização nos cursos de graduação, que deveria ser estendida para a pós-graduação; não valorizam a formação geral e cultural dos estudantes como um processo a ser construído a partir de realidade concreta, na busca de uma construção coletiva do conhecimento; desprezam as carências educacionais e culturais trazidas pelos estudantes. E com isso não conseguem superar a fragmentação do conhecimento, muito menos a organização estrutural e a prática didática - metodológicas desenvolvidas nas disciplinas.

Podemos dizer que as ações reflexivas, dialógicas, diagnósticas desenvolvidas no contexto escolar tem como objetivo garantir o direito à educação de qualidade a todos e promover a gestão democrática no sistema de ensino. Assim, a formação dos profissionais, ofertadas pelas IES, precisam pautar no campo epistemológico das diversas áreas do conhecimento, a fim de contribuir com a construção de sujeitos críticos, autônomos e capazes de lutar pela justiça social.

Nessa perspectiva, Veiga (1997) colabora com a discussão e destaca que a formação desenvolvida nos cursos superiores precisam direcionar seus planejamentos e sua estrutura nos pilares primordiais para a construção de uma educação de qualidade que sintetize na pesquisa, na produção e na divulgação do conhecimento.

Santos Filho (2006) reforça diante do cenário vivenciado que a educação desde a tenra idade até a educação superior deve apresentar alguns pontos norteadores básicos de formação, ou seja,

(1) transmitir às novas gerações o que há de mais válido da herança cultural da humanidade; (2) oferecer aos jovens e adultos a possibilidade de compreensão da cultura de seu tempo e de seu país; (3) fornecer as bases teóricas dos principais ramos do saber; (4) fornecer as bases metodológicas dos principais campos do conhecimento; (5) desenvolver nas pessoas habilidades ou competências básicas para o enfrentamento dos desafios do futuro (SANTOS FILHO, 2006, p.10).

Neste processo de elaboração e construção do conhecimento no ensino superior, observa-se que os currículos institucionais das IES precisam ser analisados e reelaborados na busca de uma educação formativa, com expressões de coletividade e humanidade. Deve partir com instrumentos de superação da permanente tensão entre o indivíduo e o coletivo, entre a liberdade e o controle, entre a independência e a interdependência.

Ristoff (1999) aponta que a educação superior deve ter o compromisso com a formação do homem, ou seja, independente da sua profissão, seja engenheiro, advogado, psicólogo, agrônomo, professor, o homem é ser humano e necessita muito mais do que um emaranhado de técnicas, métodos, 
receitas e fórmulas. Assim, formar o ser humano exige competências que vão além do conteúdo curricular e estende ao processo social, político, cultural, pedagógico, avaliativo e econômico.

Nesse sentido, a Lei de diretrizes e bases da Educação n. 9394/1996 articula em seu Art. 61 a importância da formação dos profissionais da educação e enfatiza a importância da teoria e prática estarem interligadas uma com a outra. Além disso, os cursos de formação, sejam de pedagogia, licenciaturas diversas ou de pós-graduação, deveriam valorizar o processo de formação trazido pelos alunos e suas experiências profissionais e acadêmicas, a fim de incentivar e motivar os acadêmicos em novas descobertas e ampliação de horizontes e perspectivas de mudanças.

Na formação do Inspetor Escolar, desde a Lei de Diretrizes e Bases da Educação no 5692/1971 no Art. 33, a preparação deste especialista educacional acontece em curso superior de graduação ou de pós-graduação. A diferença é que na Lei de Diretrizes e Bases da Educação no 9394/1996 destaca que essa formação deve ser garantida nos cursos de graduação em pedagogia. Não mais nos cursos superiores de graduação com duração plena ou curta. E em nível de pós-graduação, desde que seja garantida a base comum nacional.

Como ressalta Barbosa (2008), a formação do Inspetor Escolar no contexto brasileiro desde sua criação com a vinda dos Jesuítas ao Brasil em 1549 até aos dias atuais teve grandes transformações no decorrer do processo político, ideológico e histórico da educação. E muitas mudanças ainda deverão acontecer, pois este é um processo lento, que requer a prática de novas experiências com muitas idas e vindas à construção de ideias e saberes regados com sensatez, originalidade, autonomia, criatividade, postura crítica e valorização do ser humano.

Depois de alguns anos a Lei de Diretrizes de Bases da Educação Nacional 4020/1961 foi aprovada e o inspetor passou a ser submisso às normas Estaduais. Nesta norma, a qualificação deste profissional é mensurada.

A Lei n ${ }^{\circ}$ 6592/1971 altera a legislação anterior e a ação da Inspeção Escolar é ampliada com atuação também na rede particular na inspeção estadual. Alterações, também, foram destacadas quanto à formação acadêmica do Inspetor escolar. Este deveria ter formação específica em nível superior e antes de tudo ser um educador preparado na área específica.

Neste contexto, compreende-se que o processo de formação do Inspetor Escolar como gestor da educação deve orientar, preventivamente, as ações desenvolvidas na escola para o cumprimento legal e eficaz de suas finalidades: analisar e propor medidas necessárias para a regularização de vida escolar do aluno; acompanhar a elaboração dos critérios de atendimento da matrícula dos alunos, de acordo com o número de vagas, considerando a demanda escolar; analisar, junto à equipe pedagógica, os casos de classificação e reclassificação, dando as devidas orientações; participar e apreciar as 
atividades culturais promovidas pela escola dentre tantas outras atividades conforme estabelecidas pelos sistemas de ensino e secretarias de educação.

\section{CONSIDERAÇÕES FINAIS}

As transformações políticas, sociais e educacionais exigem da sociedade o atendimento à diversidade, na construção de uma cidadania plena. Com esta mudança de concepção, os sistemas educativos de formação dos gestores educacionais - professores, supervisores e inspetores escolares devem desenvolver projetos e programas a partir das diferentes características e necessidades das crianças e dos adolescentes que esses profissionais irão trabalhar.

Diante das discussões apresentadas verifica-se que a inspeção escolar numa perspectiva de construção democrática de educação tem funções e atribuições fundamentais no processo educacional. O trabalho desenvolvido pelos profissionais apresenta-se de forma mais dinâmica e orientadora, deixando em seu contexto histórico o paradigma fiscalizador.

Enfatiza-se, a partir disso, que novas posturas devem ser construídas entre os inspetores educacionais e demais profissionais da educação diante de uma reestruturação do âmbito escolar envolvendo uma mudança de transformação associada ao trabalho de equipe e liderança. Isso quer dizer, que os gestores educacionais devem estimular e promover ambientes encorajadores do reconhecimento individual, no qual prevaleçam o respeito e a valorização da sua equipe. Neste processo, as funções de liderança são distribuídas por todo o grupo de trabalho gerando um clima facilitador na resolução de problemas.

Neste processo, as instituições escolares em geral progridem e passam a apoiar seus professores, especialistas educacionais e se preocupam com o desenvolvimento do educando. Nessa dimensão passam a atuar e refletir sobre novas formas de construir a aprendizagem culminando numa reforma da educação restrita de forma a torná-la mais abrangente. Isto é, a busca na solução dos problemas conduz uma evolução do sistema de ensino que constituirá um benefício para todos os sujeitos envolvidos no processo educacional.

Percebe-se que a formação desse especialista da Educação deve priorizar seus conhecimentos com uma visão social. Assim, o assunto "Inspeção Escolar" é de fundamental importância para a construção de novos paradigmas educacionais, no qual refletem nos processos de aprendizagem dos educandos. Diante disso, a discussão da temática nos faz refletir e indagar sobre a atuação deste profissional diante das constantes mudanças políticas educacionais.

Reconhece-se que no processo da gestão democrática, as práticas educativas precisam ser intensificadas e mobilizadas no interior das escolas com o objetivo de garantir o direito à educação de qualidade a todos. Dessa forma, a coletividade, o diálogo, a escuta, a autonomia precisam ser 
trabalhadas periodicamente junto às ações educativas.

Portanto, a inspeção escolar tem papel primordial no direcionamento e orientação do processo educacional, pautado na formação plena e humana dos sujeitos, com respeito à diversidade, às diferenças e à garantia da justiça social. Não é um serviço à disposição de governos, e sim um serviço à disposição da educação, zelando pelos direitos e deveres dos atores diversos do contexto educacional. 


\section{REFERÊNCIAS}

BARBOSA, Maria Rita Leal da Silveira. Inspeção Escolar: um olhar crítico. Ed. Composer Ltda, 2008.

BRASIL. Lei no 9.394, de 20 de dezembro de 1996. Estabelece as diretrizes e bases da educação nacional. Diário Oficial da República Federativa do Brasil, Brasília, 23 dez. 1996.

BRASIL. Lei no 5.692/71. Estabelece as diretrizes e bases da educação nacional. Diário Oficial da República Federativa do Brasil, Brasília, 1971.

BRASIL, Lei $\mathbf{n}^{\mathbf{0}}$ 4020/61. Lei de diretrizes e bases da educação nacional. Diário Oficial da República Federativa do Brasil, Brasília, 1961.

CONSELHO ESTADUAL DE EDUCAÇÃO. RESOLUÇÃO nº 457, de 30 de setembro de 2009. Dispõe sobre a Inspeção Escolar na Educação Básica no Sistema Estadual de Ensino de Minas Gerais. Disponível em: https://www.jusbrasil.com.br/diarios/7320002/pg-66-executivo-diariooficial-do-estado-de-minas-gerais-doemg-de-29-01-2010. Acesso em: 02 de julho de 2021.

LAVAL, Christian. A Escola não é uma empresa: neoliberalismo em ataque ao ensino público. São Paulo: Boitempo, 2019.

RISTOFF, Dilvo Ilvo. Universidade em foco: reflexões sobre a educação superior. Florianopólis: Insular, 1999.

SANTOS FILHO, Camilo dos. Educação Geral na Universidade (mimeo). Faculdade de Educação, Unicamp, 2006.

VEIGA, Ilma Passos Alencastro (Org.). Licenciatura em Pedagogia: realidades, incertezas, utopias. Campinas/SP: Papirus, 1997, p.52-8.

UBERLÂNDIA, Prefeitura Municipal. Lei Complementar $\mathbf{n}^{\mathbf{0}}$ 661, de 8 de abril de 2019. Altera a Lei $\mathrm{n}^{\circ} 11.967$, de 29 de setembro de 2014 e suas alterações, que "Dispõe sobre o plano de carreira dos servidores do quadro da rede pública municipal de ensino de Uberlândia e dá outras providências", Disponível em: https://leismunicipais.com.br. Acesso em 02 de julho de 2021. 